\title{
Effect of nanosilver on potato plant growth and protoplast viability
}

\author{
ALI AKBAR EHSANPOUR and ZEYNAB NEJATI \\ Department of Biology, Faculty of Science, University of Isfahan, Isfahan, Iran \\ Corresponding author: Ali Akbar Ehsanpour, ehsanpou@sci.ui.ac.ir
}

(Received on 15 December 2011; Accepted on 11 February 2013)

\begin{abstract}
Potato tissue culture is sensitive to ethylene accumulation in the culture vessel. Ag inhibits ethylene action but no information on nanosilver application in potato tissue culture has been published so far. In our study, potato cv. White Desiree was treated with nanosilver $(0,1.0,1.5$, and $2.0 \mathrm{ppm})$ in vitro. Leaf surface was increased, while stem length and root length decreased. Nanosilver caused also a decrease in the number of isolated protoplasts and in the viability of isolated protoplasts when applied either directly or indirectly.
\end{abstract}

Keywords: tissue culture, ethylene, nanosilver, protoplast, potato, viability, plant growth

\section{INTRODUCTION}

The term nanosilver means nanoparticles of silver ranging in size between $1 \mathrm{~nm}$ and $100 \mathrm{~nm}$. Thus a single silver atom $(\mathrm{Ag})$ or silver ion $(\mathrm{Ag}+)$ is not nanomaterial. A nanosilver particle may or may not be charged on its surface or generate silver ions. Like ionic silver, nanosilver is a very potent killer of bacteria and has been shown to kill fungi, algae, and some viruses, including HIV (BECKER 1999). Recently, nanosilver has been found at concentrations as low as $0.14 \mu \mathrm{g} / \mathrm{ml}$ to be toxic to several species of nitrifying bacteria, which play an important role in the environment by converting ammonia in the soil to a form of nitrogen that can be used by plants (BLASER et al. 2008). Interruption of cell wall synthesis, resulting in a loss of essential nutrients, has been shown to occur in yeasts (WeLLs et al. 1995) and may occur in other fungi as well. Antiviral activity of silver ions has been recorded, and interaction with - $\mathrm{SH}$ groups has been implicated in the mode of action (ThuRMAN \& GERBA 1989).

Plant tissue cultures incubated in vitro emanate ethylene, and accumulation of this plant hormone in the culture vessel headspace may be unfavourable to culture growth. Potato explants are very sensitive to ethylene accumulation. Under in vitro culture of potato explants, ethylene causes slow growth, small leaf size, weak stems, and root formation on shoots (EHSANPOUR \& JONES 2000). To overcome this problem, 
silver ion $\left(\mathrm{Ag}^{+}\right)$can be applied, as silver nitrate $\left(\mathrm{AgNO}_{3}\right)$ or in the form of a silver thiosulfate (STS) complex, since it is an effective inhibitor of ethylene action (BEYER 1979; VEen \& VAN De GeIJn 1978). Recently, Strader et al. (2009) found that in addition to blocking ethylene signalling, $\mathrm{Ag}^{+}$promotes indole-3-acetic acid (IAA) efflux. Silver added to the medium has been used to control and improve plant regeneration and transformation in vitro (KUMAR et al. 1998; KUMAR et al. 2007). Improvements were achieved despite the phytotoxicity of $\mathrm{AgNO}_{3}$ (RATTE 1999). $\mathrm{Ag}^{+}$reacts not only with halide ions, but also binds to various compounds - such as lipopolysaccharides, amino acids, proteins, RNA, and DNA - to form silver nanoparticles, a property frequently used for biochemical analyses (BLum et al. 1987, SHEVCHENKo et al. 1996; TSAI \& FRASCH 1982). This is the first study aimed to answer if nanosilver is able to block ethylene function of potato plants under tissue culture conditions and if nanosilver is toxic to potato as a model plant.

\section{MATERIAL AND METHODS}

The virus-free potato cv. White Desiree was obtained from shoot culture stock of the Department of Biology, University of Isfahan, Iran. Single-node stem segments were sub-cultured on MS (Murashige \& SKOOG 1962) basal medium without growth regulators. Explants (stem segments $1 \mathrm{~cm}$ long) were taken from 4-week-old in vitro plantlets and were transferred onto MS medium containing 0, 1.0, 1.5, and $2.0 \mathrm{mg} / 1$ nanosilver $(50 \mathrm{~nm})$. Plants were grown in the culture room at $25^{\circ} \mathrm{C}$ with $16-\mathrm{h}$ photoperiod and a photosynthetic photon flux density of $95 \mu \mathrm{mol} \mathrm{m} \mathrm{m}^{-2} \mathrm{~s}^{-1}$. All experiments were carried out with 4 replications.

\section{Protoplast isolation}

Leaf segments from 4-week-old potato plants treated with various concentrations of nanosilver and untreated plants as control were used for protoplast isolation. Approximately $0.5-1.0 \mathrm{~g}$ of large leaves were removed, cut into thin $(0.5-1.0 \mathrm{~mm})$ strips, and soaked (pre-plasmolysed) in wash solution (FISH \& KARP 1986) containing $7.5 \%$ mannitol, $\mathrm{pH} 5.6$, for $0.5-1.0 \mathrm{~h}$. Protoplasts were released by gently swirling the leaf slices for $4.5 \mathrm{~h}$ at $40 \mathrm{rpm}$ at $25-28^{\circ} \mathrm{C}$ in an enzyme solution containing the major salts of FiSH \& KARP (1986), macerozyme R-10 (0.15\%, Yakult Tokyo, Japan), cellulase $(0.7 \%)$, pH 5.6, and then centrifuged at $700 \mathrm{rpm}$ for $5 \mathrm{~min}$. Protoplasts were re-suspended and washed twice in wash solution. The density of protoplasts was determined by counting the number of protoplasts in a homocytometer. The viability of protoplasts was also examined, using fluorescein diacetate (FDA, $5 \mathrm{mg} / \mathrm{l}$ ), as described by TempelaAR \& Jones (1985). After 4 weeks, the ratio of leaf surface to shoot length, root length, the number of isolated protoplasts, and protoplast viability were recorded.

\section{Direct effect of nanosilver on protoplast viability}

Protoplasts were isolated from a 4-week-old untreated potato plant. Next, a few drops of protoplast suspension $\left(3 \times 10^{4} / \mathrm{ml}\right)$ were loaded on the microscope slide and 
covered by a cover slip. Then nanosilver ( $2.0 \mathrm{ppm})$ was added to the protoplasts and the viability of protoplasts was monitored for $12 \mathrm{~min}$ by taking photos of protoplasts every 3 min.

\section{RESULTS}

The effects of different concentrations of nanosilver on the ratio of leaf surface to shoot length showed that the application of nanosilver at a concentration of $0.5,1.0$, 1.5 , and $2.0 \mathrm{ppm}$ increased this ratio. It means that leaf surface of potato plant was increased, whereas shoot length was decreased due to nanosilver treatment (Fig. 1).

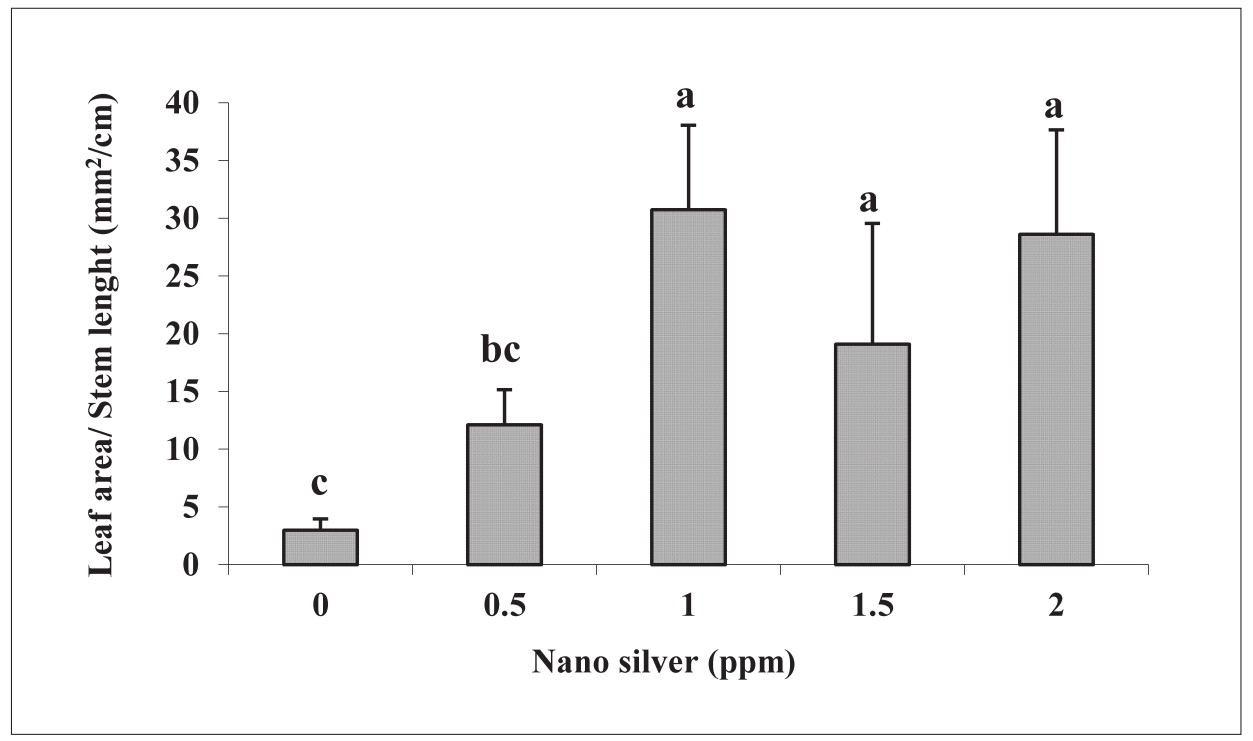

Fig. 1. Effect of nanosilver on leaf area to shoot length ratio of potato plants.

Different letters denote significant differences $(P \leq 0.05$, Duncan test). Error bars denote standard deviation

When the root lengths of treated plants were measured, data showed that nanosilver treatment had decreased root length. Potato plants under 1.5 and $2.0 \mathrm{ppm}$ did not produce any roots or just a few roots were initiated (Fig. 2)

From the plants treated with nanosilver and the untreated plants, protoplasts were isolated. The number of protoplasts released from leaf segments of treated plants with nanosilver $(0.5,1.0,1.5,2.0 \mathrm{ppm})$, compared to the untreated plants, decreased significantly. A dramatic reduction of the number of protoplasts was observed when 


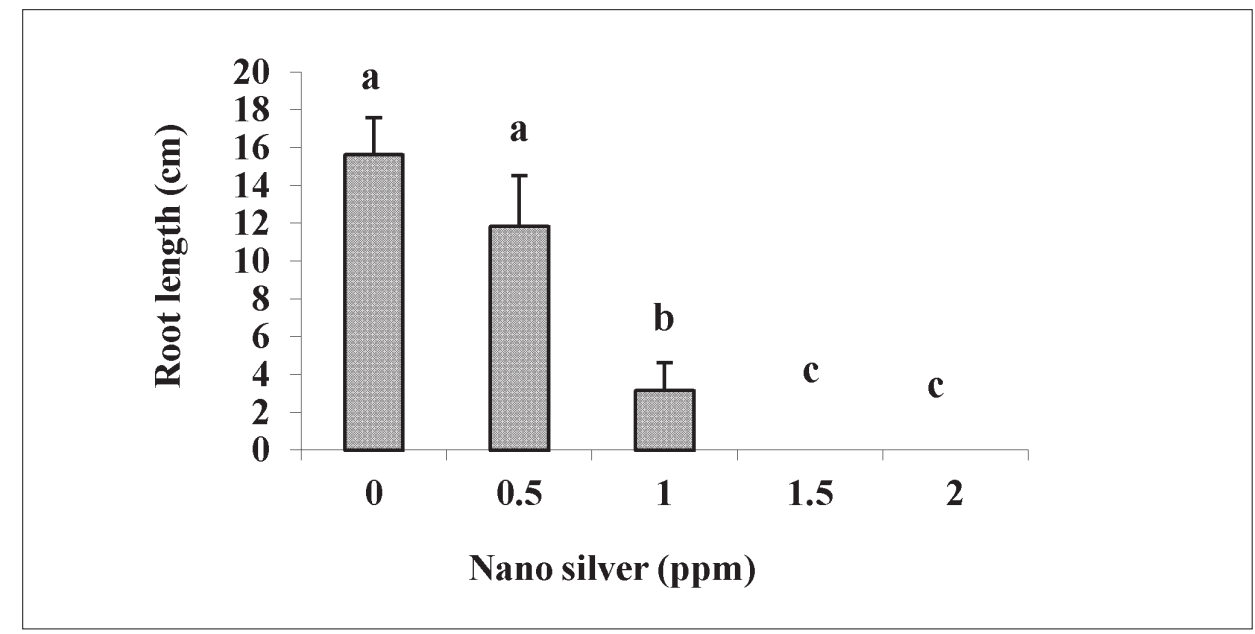

Fig. 2. Effect of nanosilver on root length of potato plants. Different letters denote significant differences $(P \leq 0.05$, Duncan test). Error bars denote standard deviation

nanosilver was applied at concentrations higher than 0.5 ppm (Fig. 3). A similar pattern was observed for protoplast viability. Compared to the control (60\%), plant treatment with nanosilver resulted in significantly lower viability. For example, at 0.5 and $1.0 \mathrm{ppm}$, approximately $30 \%$, and at 1.5 and $2.0 \mathrm{ppm}$ nanosilver, slightly less than $20 \%$ of isolated protoplasts were viable (Fig. 4).

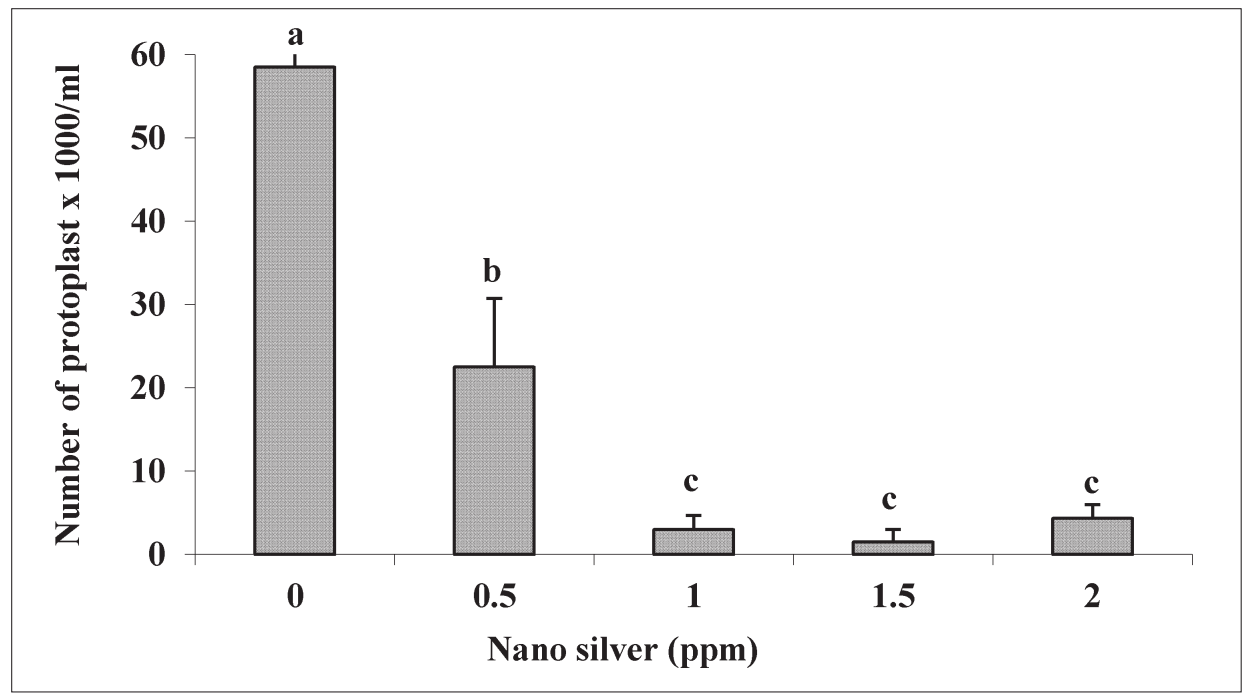

Fig. 3. Effect of nanosilver on number of isolated protoplasts from potato plants. Different letters denote significant differences $(P \leq 0.05$, Duncan test). Error bars denote standard deviation 
The viability of protoplasts was decreased when nanosilver was applied directly on protoplasts of the untreated plants (Fig. 5). The dramatic and quick reduction of protoplast viability within 9 min led to complete death of protoplasts (Fig. 6).

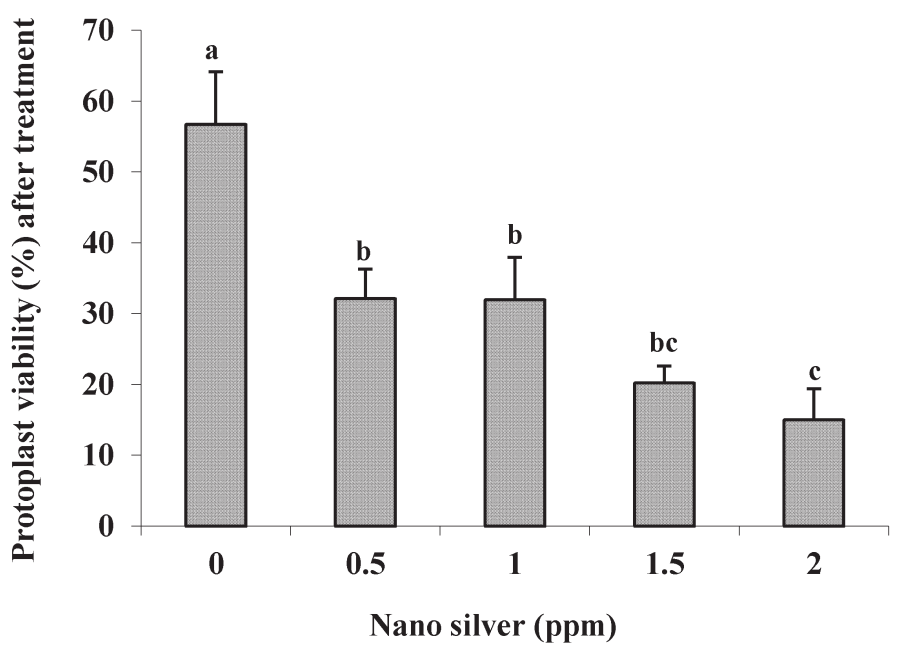

Fig. 4. Effect of nanosilver on viability of protoplasts isolated from potato plants treated with nanosilver. Different letters denote significant differences $(P \leq 0.05$, Duncan test $)$. Error bars denote standard deviation

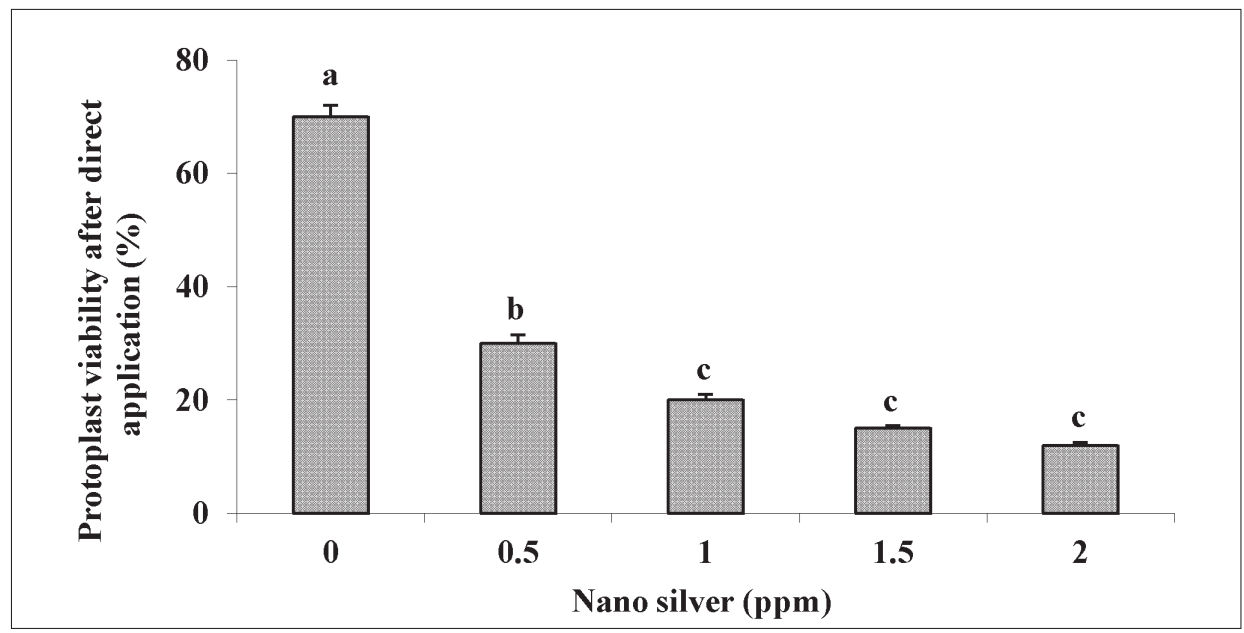

Fig. 5. Effect of direct application of nanosilver on viability of isolated protoplasts from control plants. Different letters denote significant differences $(P \leq 0.05$, Duncan test). Error bars denote standard deviation 


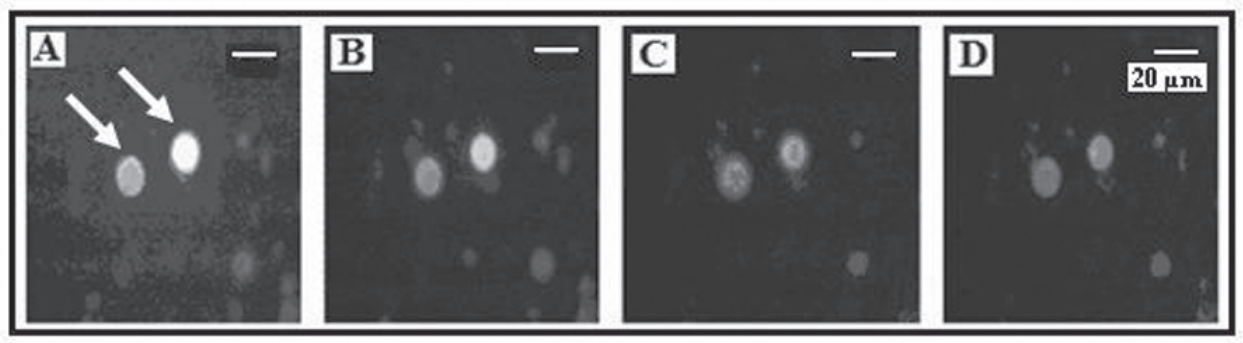

Fig. 6. Effect of direct application of nanosilver on protoplast viability within 9 min. Light green colour (indicated by arrows) is viable protoplast at time 0 (A), after $3 \mathrm{~min}$ (B), after $6 \mathrm{~min}$ (C), after 9 min (D). Red colour shows nonviable protoplasts

\section{DISCUSSION}

It has been reported that a decrease in explant survival and biomass reduction after nanosilver treatment is related to malformation of roots and inhibition of shoot formation in chrysanthemum and tobacco. Silver ions interact with sulfhydryl (-SH) groups of proteins as well as with the bases of DNA, leading either to the inhibition of respiratory processes (BRAGG \& RANNIE 1974) or DNA unwinding (BATARSEH 2004). Inhibition of cell division and damage to bacterial cell envelopes are also recorded (RichARDS et al. 1984) and interaction with hydrogen bonding processes has been demonstrated to occur (Russell \& Hugo 1994). As specific surface area of nanoparticles is increased, their biological effectiveness can be increased due to the increase in surface energy (WILLEMS 2005).

The development of aerial roots, branching, and scale leaves on the cultured potato cv. White Desiree shoots usually occur if it is cultured in tightly closed vessels. This phenomenon has been reported for other plants as well, for example Brassica campestris L. This phenomenon is caused by accumulation of ethylene and depletion of oxygen in the tissue culture vessel. Ethylene reduces the frequency of adventitious shoot regeneration from explants and retards potato growth (ADKINS et al. 1993, CHANG \& CHAN 1991) and also inhibits rice callus growth (AdKIns \& Magdalita 1994). One of the obvious effects of ethylene accumulation is small leaf surface area. The effects of ethylene on potato tissue culture might be due to the interaction between endogenous growth-promoting hormones and ethylene (CHI \& PUA 1989). PERL et al. (1988) reported that ethylene inhibits cell division and cell differentiation in lettuce pith explants. A similar report by APELBAUM \& BURG (1972) indicated that cell division frequency is reduced by $95-98 \%$ in the hook region of Pisum sativum treated with $50 \mu \mathrm{M}$ ethylene. Inhibition of ethylene action by STS or ethylene synthesis by ancymidol has been proved to affect potato growth and development. Application of nanosilver on potato cv. White Desiree showed that it affected leaf and stem growth very much like STS. Nanosilver at all concentrations $(0.5,1.0,1.5,2.0$ $\mathrm{ppm}$ ) caused an increase in leaf surface area but a decrease in shoot length. Increasing 
of leaf surface to shoot length ratio has been reported already using STS (EHSANPOUR \& JONES 2001). Root length was decreased when nanosilver was applied at a concentration of 0.5 or $1.0 \mathrm{ppm}$, whereas no root growth was observed at 1.5 and $2.0 \mathrm{ppm}$. The inhibitory effect of nanosilver might be due to toxicity of silver nanoparticles, in particular at concentrations higher than $0.5 \mathrm{ppm}$.

Improvement of protoplast isolation using ethylene inhibitors, such as STS, has already been reported for potato (EHSANPOUR \& JONES 2001). In that report, also the viability of protoplasts was increased by STS. In contrast, when nanosilver was added to the culture medium in the present study, the number of isolated protoplasts and percentage of viable protoplasts of potato cv. White Desiree decreased dramatically. Since silver nanoparticle has no electric charge, it can easily move to the cytoplasm through cell membrane, and inside the cell it can be accumulated at a high concentration. This may happen either indirectly, when nanosilver is added to the culture medium, or directly, when nanosilver is applied directly onto the isolated protoplasts. Consequently, the high toxicity of nanosilver, due to the generation of reactive oxygen species (ROS) in the protoplast, reduces the number and viability of isolated protoplasts. Surprisingly, recently it has been reported that silver nanoparticle is able to generate ROS and has a poisonous effect on plant cells of Arabidopsis thaliana (ARIFA et al. 2012). In our experiments, inhibition of potato root growth also might be a consequence of ROS production. There are 2 possible ways for ethylene receptor inhibitory function of nanosilver in the cell: (1) it may occur inside the cytoplasm as nanoparticles and make a nanoparticle coat on the ethylene receptor and block the ethylene action, or (2) inside the cytoplasm nanosilver may be converted to silver ions and act like $\mathrm{AgNO}_{3}$ and STS (HAKAN 2004). However, in either case, despite improvement in some parameters of growth and development of potato plants, nanosilver caused a dramatic loss of viability of isolated protoplasts. This is the first report to indicate that nanosilver is a toxic agent for potato plant cells.

Acknowledgments: We would like to thank the University of Isfahan and Plant Stress Centre of Excellence (PSCE) for their support.

\section{REFERENCES}

Adkins S. W., Kunanuvatchaidach R., Gry S. J., Adkins A. L. 1993. Effect of ethylene and culture environment on rice callus proliferation. J. Exp. Bot. 44: 1829-1853.

Adkins S.W., Magdalita P. 1994. The gaseous envelope effect of ethylene on culture performance. In: Abstracts of VIIIth International Congress of Plant Tissue and Cell Culture. June 12-17, 1994, Firenze, Italy, p. 213.

Apelbaum A., Burg S. P. 1972. Effect of ethylene on cell division and deoxyribonucleic acid synthesis in Pisum sativum. Plant Physiol. 50: 117-124.

Arifa S., Subramanim S., Lawson, T., Avistunenko D., Colbeck L., Demidchik V. 2012. Nanoparticle inhibit root and leaf growth, induce generation of reactive oxygen species and trigger elevation of cytosolic calcium in Arabidopsis thaliana. In: Abstracts of Plant Biology Congress. 29 July - 3 August, 2012, Albert - Ludwigs - University Freiburg, Germany, p 296. 
Batarseh K. I. 2004. Anomaly and correlation of killing in the therapeutic properties of silver (I) chelation with glutamic and tartaric acids. J. Antimicrob. Chemother. 54: 546-548.

BECKER R. O. 1999. Silver ions in the treatment of local infections. Met. Based Drugs 6: 297-300.

BEYER E. M. 1979. Effect of silver ion, carbon-dioxide, and oxygen on ethylene action and metabolism. Plant Physiol. 63: 169-173.

Blaser S. A., Scheringer M., MacLeod M., Hungerbühler K. 2008. Estimation of cumulative aquatic exposure and risk due to silver: Contribution of nano-functionalized plastics and textiles. Sci. Total Environ. 390: 396-409.

Blum H., Beier H., Gross H. J. 1987. Improved silver staining of plant-proteins, RNA and DNA in polyacrylamide gels. Electrophoresis 8: 93-99.

Bragg P. D., Rannie D. J. 1974. The effect of silver ions on the respiratory chain of E. coli. Can. J. Microbiol 20: 883-889.

Chang H. H., Chan M. T. 1991. Improvement of potato (Solanum tuberosum L.) transformation by Agrobacterium in presence of silver thiosulphate. Bot. Bull. Acad. Sinica 32: 63-70.

ChI G. L., PuA E. C. 1989. Ethylene inhibitors enhanced de novo shoot regeneration from cotyledons of Brasicca campestris ssp chinensis (Chinese cabbage) in vitro. Plant Sci. 64: 243-250.

Ehsanpour A. A., Jones M. G. K. 2001. Plant regeneration from mesophyll protoplasts of potato (Solanum tuberosum L.) cultivar Delaware using silver thiosulfate (STS). J. Sci. I. Rep. Iran. 12: 103-110.

FisH N., KARP A. 1986. Improvements in regeneration from protoplasts of potato and studies on chromosome stability. The effect of initial culture media. Theor. Appl. Genet. 72: 405-412.

HAKAN T. 2004. The effect of silver nitrate (ethylene inhibitor) on in vitro shoot development in potato (Solanum tuberosum L.). Biotechnology 3: 72-74.

Kumar P. P., Lakshmanan P., Thorpe T. A. 1998. Regulation of morphogenesis in plant tissue culture by ethylene. In Vitro Cell. Dev. Biol. Plant. 34: 94-103.

Kumar V., Ramakrishna A., Ravishankar G. A. 2007. Influence of different ethylene inhibitors on somatic embryogenesis and secondary embryogenesis from Coffea canephora P ex Fr. In Vitro Cell. Dev. Biol. Plant 43: 602-607.

Murashige T., Skoog F. 1962. A revised medium for rapid growth and bioassays with tobacco tissue cultures. Physiol. Plant 15: 473-497.

Perl A., Aviv D., Galun E. 1988. Ethylene and in vitro culture of potato: suppression of ethylene generation vastly improves protoplast yield, plating efficiency and transient expression of an alien gene. Plant Cell Rep. 7: 403-406.

Ratte H. T. 1999. Bioaccumulation and toxicity of silver compounds: A review. Environ. Toxicol. Chem. 18: 89-108.

Richards R. M. E., TAYlor R. B., Xing D. K. L. 1984. Effect of silver on whole cells and spheroplasts of a silver resistant Pseudomonas aeruginosa. Microbios 39: 151-158.

Russell A. D., Hugo W. B. 1994. Antimicrobial activity and action of silver. Prog. Med. Chem. 31: 351-371.

Shevchenko A., Wilm M., Vorm O., Mann M. 1996. Mass spectrometric sequencing of proteins from silver-stained polyacrylamide gels. Anal Chem 68: 850-858.

Strader L. C., Beisner E. R., Bartel B. 2009. Silver ions increase auxin efflux independently of effects on ethylene response. Plant Cell. 21: 3585-3590.

Tempelaar M., Jones M. G. K. 1985. Directed electrofusion between protoplasts with different responses in a mass fusion system. Plant Cell Rep. 4: 92-95.

Thurman R. B., Gerba C. P. 1989. The molecular mechanisms of copper and silver ion disinfection of bacteria and viruses. CRC Crit. Rev. Environ. Control. 18: 295-315.

Tsai C. M., Frasch C. E. 1982. A sensitive silver stain for detecting lipopolysaccharides in polyacrylamide gels. Anal. Biochem. 119: 115-119.

Veen H., van de GeIJN S. C. 1978. Mobility and ionic form of silver as related to longevity of cut carnations. Planta 140: 93-96. 
Wells T. N., Scully P., Paravicini G., Proudfoot A. E., Payton M. A. 1995. Mechanism of irreversible inactivation of phosphomannose isomerases by silver ions and flamazine. Biochemistry 34: 896-903.

WiLlems W. 2005. Roadmap report on nanoparticles. W\&W Espana sl, Barcelona, Spain. 